\title{
Realising the Right to Health during the COVID-19 Pandemic
}

\author{
An Antidote to the Pandemic and the Catalyst for Fulfilling a Long-Neglected \\ Social Right?
}

Ingrid Nifosi-Sutton*

\section{Introduction}

Since the inception of the COVID-19 pandemic competent authorities in many States have undertaken herculean efforts to protect the health, safety and lives of affected persons and communities. Yet the path to the effective management and eventual defeat of the novel coronavirus is arduous, has an immense human and economic cost, and is prone to setbacks.

Against this background this article posits that implementation of the internationally recognised right to health can contribute to an effective management of the COVID-19 pandemic, while the pandemic itself may constitute the catalyst for realising the right to health, a long-ignored and overlooked [...] social [right]'.'

This article develops its main thesis as follows. Part 2 introduces the right to health by discussing its legal significance and contour under international human rights law.

Part 3 highlights the relevance of the right to health to the CoviD-19 pandemic and the added value of its implementation for the purposes of an effective pandemic response. To this aim, Part 3 elucidates how UN human rights monitoring bodies (UNMB) have construed new entitlements flowing from the right to health and its essential elements of health care availability, accessibility, acceptability, and quality in the context of the COVID-19 pandemic. Through reliance on these interpretations and an overview of trends in State practice Part 3 shows that the realisation of the right to health contributes to shape pandemic responses that: a) foster community's participation and government accountability; b) are well equipped to tackle the formidable public health challenges coviD-19 poses; c) are inclusive and successful since

Adjunct Associate Professor of Law, American University Washington College of Law.

1 HRC 'Climate change and poverty. Report of the Special Rapporteur on extreme poverty and human rights' (25 June 2019) A/HRC/41/39, para. 55 . 
they prioritise the health needs of those most at risk of CoviD-19, especially marginalised groups, and provide these persons with CoviD-19 treatments specifically tailored to their predicaments; d) are fair in so far as they support vaccination efforts worldwide; and e) ensure that Covid-19 treatments are culturally acceptable, respectful of medical ethics and medically appropriate. The UNM B considered for the purposes of Part 3 are: the Committee on Economic, Social and Cultural Rights; the Committee on the Elimination of Discrimination against Women; the Committee on the Rights of Persons with Disabilities; the Committee on the Elimination of Racial Discrimination; the Committee on the Rights of the Child; the Committee on Migrant Workers; the UN Special Procedures; the Special Rapporteur on the human rights of migrants; and the Special Rapporteur on the right to health. ${ }^{2}$

Part 4 demonstrates that the COVID-19 pandemic is functioning as a catalyst for realising the long-overlooked right to health. Part 4 briefly revisits arguments States have put forward against the legal nature of economic, social and cultural rights and which contributed to the neglect of these rights. After showing that economic, social and cultural rights are "true" legal rights, Part 4 points to developments in the practice of pandemic-affected States indicating that States are renewing efforts to implement the right to health when addressing the short, medium and long-term public health challenges COVID-19 presents.

This essay concludes by offering a summary of its main analytical findings and some final remarks.

\section{The Right to Health under International Human Rights Law}

The right to health is enshrined in a wide array of UN and regional human rights instruments. First and foremost is the 1966 International Covenant on Economic, Social and Cultural Rights (ICESCR), which in Article 12 sets forth 'the right of everyone to the enjoyment of the highest attainable standard of physical and mental health.' ${ }^{3}$ Article 12 stems from Article 25 (1) of the 1948 Universal Declaration of Human Rights containing everyone's 'right to a

2 Regional monitoring bodies have put forward interpretations of the right to health in the context of the Covid-19 pandemic too. These interpretations are however beyond the scope of this essay. For further analysis see: Lisa Reinsberg, 'Mapping the Proliferation of Human Rights Bodies' Guidance on COviD-19 Mitigation' (2020) Just Security <https://www .justsecurity.org/70170/mapping-the-proliferation-of-human-rights-bodies-guidance-on -covid-19-mitigation/>.

3 The Covenant is available at $<$ https://www.ohchr.org/en/professionalinterest/pages/cescr .aspx>. 
standard of living adequate for the health and well-being of himself and of his family, including (...) medical care'.

At the UN level the right to health is also enunciated in

- Article 5 (e) (iv) of the 1965 International Convention on the Elimination of All Forms of Racial Discrimination (ICERD);

- Articles 11(1) (f) and 12 of the 1979 UN Convention on the Elimination of All Forms of Discrimination against Women (UNCEDAW);

- Article 24 of the 1989 UN Convention on the Rights of the Child (UNCRC); and

- Article 25 of the 2006 UN Convention on the Rights of Persons with Disabilities (UNCRPD). ${ }^{4}$

At the regional level the right to health is recognised in

- Article 11 of the 1996 Revised European Social Charter (RESC);

- Article 16 of the 1981 African Charter on Human and Peoples' Rights;

- Article 14 of the 1990 African Charter on the Rights and Welfare of the Child (ACRWC); and

- Article 10 of the 1988 Additional Protocol to the American Convention on Human Rights in the Area of Economic, Social and Cultural Rights (Protocol of San Salvador). ${ }^{6}$

Article 12 of the ICESCR, Article 24 of the UNCRC and Article 25 of the UNCRPD refer to the right to health as the right to the enjoyment of the highest attainable standard of physical and mental health. While these treaties enshrine 'the formulation of the right to health adopted in international law,' 7 the other treaties enumerated above use different language. For example, article 14 of the ACRWC incorporates 'the right to enjoy the best attainable state of physical, mental and spiritual health', and Article 10 of the Protocol of San Salvador codifies the right to the enjoyment of the highest level of physical, mental and social well-being. While Article 11 of the RESC enshrines the right to protection of health, Article 5 (e) (iv) of the ICERD sets forth the right to public health. Article 12 of the UNCEDAW, on the other hand, omits explicit reference to the right to health to codify the State obligation to 'ensure, on a basis of equality of men and women, access to health care services, including those related to family planning'.

For the sake of completeness, it is important to underscore that the InterAmerican Court of Human Rights has interpreted Article 26 of the 1969

4 OHCHR, 'International Standards on the Right to Physical and Mental Health' <https://www .ohchr.org/EN/Issues/Health/Pages/InternationalStandards.aspx>.

5 The Revised Charter sets out the rights guaranteed by the European Social Charter of 1961 and its additional Protocol of 1988 , and adds new rights adopted by its Parties.

6 'International Standards on the Right to Physical and Mental Health' (n 4).

7 John Tobin, The Right to Health Under International Law (OUP 2012) 123. 
American Convention on Human Rights, enshrining economic, social and cultural rights (ESCR), as encompassing an autonomous right to enjoy the highest attainable standard of health. ${ }^{8}$

Although, as shown in Part 4 of this essay, States have overlooked the implementation of the right to health, the right to health can be considered to be at present a norm of customary international law. Adherence by most States to the above multilateral treaties setting out the right to health signals widespread recognition of this right and the undertaking to give effect to it. Moreover, the right to health is contained in domestic constitutions, laws and programs; ${ }^{9}$ and has been recognised and reaffirmed in various declarations and resolutions of international and regional organizations. ${ }^{10}$ The writing of scholars further bears out that the right to health has crystallised in a norm of international customary law. ${ }^{11}$

\subsection{The Normative Content of the Right to Health}

Human Rights monitoring bodies have put forward a dynamic, multifaceted and 'inclusive'12 notion of the international right to health. This notion is quasi-medical, socio-economic, cultural, and biological, and based on the recognition that individuals' physical and emotional well-being necessitates a holistic approach not limited to mere absence or mitigation of diseases. ${ }^{13}$

8 IACtHR, Case of Cuscul Pivaral et al. v. Guatemala, Judgement, (23 August 2018), paras. 72-127; Case of Poblete Vilches et al. v. Chile, Judgement, (8 March 2018), paras. 10o103 and 106-110; Oona A. Hathaway et al., 'COVID-19 and International Law Series: Human Rights Law-Right to Health' (2020) Just Security <https://www.justsecurity .org/73447/covid-19-and-international-law-series-human-rights-law-right-to-health/>.

$9 \quad$ Eleanor D. Kinney, 'The International Human Right to Health: What Does This mean For Our Nation and World?' (2001) 34 (4) Indiana Law Review, 1466; Paul Hunt, 'Interpreting the International Right to Health in a Human Rights-Based Approach to Health' (2016) Health and Human Rights Journal <https://www.hhrjournal.org/2016/12/interpreting-the -international-right-to-health-in-a-human-rights-based-approach-to-health/\#_edn33>; онCHR/wHO, 'The Right to Health' (2008) 10-11, <https:/www.ohchr.org/documents/ publications/factsheet31.pdf >.

10 See inter alia 'International Standards on the Right to Physical and Mental Health' (n 4).

11 See Kinney (n 9) 1464; Alicia Yamin, "The Right to Health Under International Law and Its Relevance to the United States' (2005) 95/7 American Journal of Public Health, 1156-1161, <https://www.ncbi.nlm.nih.gov/pmc/articles/PMC1449334/>; John Tobin (n 7) 18-19, 46-47; and Lawrence O. Gostin et al., 'Facilitating Access to a COVID-19 Vaccine through Global Health Law' (2020) 48/3 The Journal of Law, Medicine \& Ethics, 623-624.

12 CESCR, 'General Comment No. 14 (2000). The right to the highest attainable standard of health (article 12 of the International Covenant on Economic, Social and Cultural Rights)' (11 August 2000) E/C.12/200o/4, para. 11.

13 Ibid., paras. 9 and 11; Inter-American Commission on Human Rights, 'Report on Trans and Gender Diverse Persons and Their Economic, Social and Environmental Rights' (7 August 2020) OEA/Ser.L/v/II Doc. 239, para. 316. 
Hence, the right to health should not be equated to a right to good health as the implementation of such a standard would place an undue burden on the State and create unrealistic expectations as to what the State can do to preserve and promote the health of individuals and communities. ${ }^{14}$ The drafting history of the ICESCR and the UNCRC bears out that the notion of the right to health is complex and wide-ranging. ${ }^{5}$

All monitoring bodies have embraced a quasi-medical notion of the right to health in the sense that they fundamentally understand this right as a right to access 'timely and appropriate health care'16 rather than a right to be healthy. Health care encompasses health facilities, goods, and services ${ }^{17}$ instrumental in preventing, detecting and treating illnesses; ${ }^{18}$ and providing rehabilitative and palliative care. ${ }^{19}$ As the Committee on Economic, Social and Cultural Rights (CESCR), the Committee on the Elimination of Discrimination against Women (CEDAW) and the Committee on the Rights of Persons with Disabilities (CRPD) have pointed out, access to health care also comprises access to sexual and reproductive health services for women and girls, including women and girls with disabilities. ${ }^{20}$ Furthermore, access to health care extends to access to mental health care services ${ }^{21}$ and medicines. ${ }^{22}$

14 ECSR, Transgender Europe and ILGA-Europe v. the Czech Republic, Decision on the Merits, (15 May 2018), para. 71; General Comment No. 14 (n 12) paras. 8-9.

15 See John Tobin (n 7) 131.

16 General Comment No. 14 (n 12) para. 11. See also CRPD, 'General comment No. 1 (2014). Article 12: Equal recognition before the law' (19 May 2014) CRPD/C/GC/1, para. 41; and CRC, 'Concluding observations on the combined fifth and sixth periodic reports of Belarus' (28 February 20200) CRC/C/BLR/CO/5-6, para. 32 .

17 General Comment No. 14 (n 12) paras. 9 and 17; Case of Cuscul Pivaral et al.v. Guatemala (n 8) para. 105; ACH PR, Communication 431/12 - Thomas Kwoyelo v. Uganda, (17 October 2018), para. 274. See also Marlies Hesselman and Brigit Toebes, 'The Human Right to Health and Climate Change: A Legal Perspective' (2015) Global Health Law Groningen Working Paper, 4.

18 See in particular General Comment No. 14 (n 12$)$ para. 17.

19 CRC, 'General comment No. 15 (2013) on the right of the child to the enjoyment of the highest attainable standard of health (art. 24)' (17 April 2013) CRC/C/GC/15, para. 2.

20 General Comment No. 14 (n 12) para. 14; CRPD, 'General comment No. 3 (2016) on women and girls with disabilities' (25 November 2016) CRPD/C/GC/3, para. 28; CEDAW 'General recommendation No. 24: Article 12 of the Convention (women and health)' (1999), para. 1.

21 General Comment No. 14 (n 12) para. 17; ACHPR, 241/o1: Purohit and Moore v. Gambia (The), (15-29 May 2003), para. 83; CESCR, 'Concluding observations on the seventh periodic report of Ukraine' (2 April 2020) E/C.12/U KR/CO/7, paras. 4O-41.

22 General Comment No. 14 (n 12) para. 17; HRC 'Report of the Special Rapporteur on the right of everyone to the enjoyment of the highest attainable standard of physical and mental health, Anand Grover' (31 March 2009) A/HRC/11/12, para. 10 (a). 
The Monitoring bodies have made clear that the notion of the right to health also encapsulates a panoply of underlying determinants of health. These determinants can be socio-economic, cultural and biological. They include inter alia: food; housing; access to safe water and sanitation; safe and healthy working conditions; a healthy environment; socio-economic status; cultural paradigms; and one's age, sex, and health status. ${ }^{23}$

From the point of view of State responsibility, the right to health imposes obligations to respect, protect and fulfil to the maximum of States' available resources ${ }^{24}$ including those obtainable through international assistance and cooperation..$^{25}$ A myriad of specific State obligations flow from the above three general obligations. When it comes to the right to health as enshrined in the ICESCR, the CESCR makes clear in paragraphs $34^{-36}$ of General Comment No. 14 , containing the most authoritative interpretation of the right to health, ${ }^{26}$ that depending on their contents these specific obligations may be performed immediately or subject to progressive realisation. This clarification is welcome since it provides States with guidance on how to realise the right to health and debunks the argument that this right can only be implemented progressively. Among immediate obligations, there are some that should be actualised as a matter of priority. The Committee labels them as core non-derogable obligations concerned with the satisfaction of minimum essential levels of the right to health ${ }^{27}$ 'beneath which no state [party to the ICESCR] can be permitted to

23 General Comment No. 14 (n 12) paras. 9 and 11; General comment No. 15 (n 19), paras. 16-18; ACHPR, 155/96: Social and Economic Rights Action Center (SERAC) and Center for Economic and Social Rights (CESR) / Nigeria, (27 October 2001), para. 53; ECSR European Roma Rights Centre (ERRC) v. Bulgaria, Decision on the Merits, (5 December 2018), para. 36. See also Marlies Hesselman and Brigit Toebes (n 17).

24 General Comment No. 14 (n 12) paras. 33-37 and 47; General comment No. 15 (n 19) para. 71; General recommendation No. 24 (n 20) paras. 13-17; SERAC case (n 23) paras. 44 and 52; and Marlies Hesselman and Brigit Toebes (n 17) 12-14.

25 General Comment No. 14 (n 12) para. 38; Report of the Special Rapporteur on the Right to Health (n 22) para. 11.

26 Brigit Toebes, Lisa Forman and Giulio Bertolini, 'Towards Human Rights-Consistent Responses to Health Emergencies: What is the Overlap between Core Right to Health Obligations and Core International Regulation Capacities?' (2020) 22 (2) Health and Human Rights Journal, 101.

27 CESCR 'General Comment No. 3: The Nature of States Parties' Obligations (art. 2, para. 1, of the Covenant)' (1990), para. 10; Toebes et al. (n 26) 103; Ben Saul, David Kinley and Jacqueline Mowbray, 'Article 2 (1): Progressive Realization of ICESCR Rights' in Bel Saul, David Kinley and Jacqueline Mowbray (eds), The International Covenant on Economic, Social and Cultural Rights: Commentary, Cases, and Materials (OUP 2014) 145-16. 
fall':28 These obligations require: 1) ensuring access to health facilities, goods and services on a non-discriminatory basis, especially for marginalised groups; 2) ensuring equal access to adequate food; 3 ) ensuring access to basic shelter, housing, sanitation, and potable water; 4) providing essential medicines; 5) facilitating equitable distribution of health care systems; and 6) adopting and implementing a national public health strategy and plan of action. ${ }^{29}$

Academic debate of the core obligations has been vibrant and produced questions about the demands they place on the State and the CESCR's authority to develop them..$^{30}$ Nevertheless, a perusal of the Committee's monitoring practice demonstrates that the Committee continues to regard the core obligations as duties integral to the realisation of the right to health and to be prioritised even in times of resource constraints ${ }^{31}$ and during emergencies. ${ }^{32}$ The burden is on non-compliant parties to the ICESCR to convincingly show 'that every effort [was] made to use all resources (...) at [their] disposal (...) to satisfy, as a matter of priority, [the] minimum obligations. ${ }^{33}$ For the Committee the core obligations constitute indispensable steps to be taken to fully realise the right to health, including in 'crisis setting[s], where resources are limited and there are surging needs for urgent health care. ${ }^{34}$ These obligations are instrumental in averting indefinite delay or regression in the implementation of the right to health that would deprive this right, and by extension, the ICESCR of their raison d'être. ${ }^{35}$

28 Ben Saul et al. (n 27) 145.

29 General Comment No. 14 (n 12) para. 43.

30 See Tobin (n 7 ) 240; and Toebes et al. (n 26). For further critical analysis of the core obligations see also Katharine G. Young, 'The Minimum Core of Economic and Social Rights: A Concept in Search of Content' (2008) 33 Yale Journal of International Law, 113-174.

CESCR, 'Concluding observations on the second to the fifth periodic report of India' (8 August 2008) E/C.12/IND/Co/5, para. 45; 'Concluding Observations on the initial report of South Africa' (29 November 2018) E/C.12/ZAF/Co/1, paras. 18-19 (a), 63 and 64 (b) and (c); 'Concluding Observations on the fourth periodic report of Ecuador' (14 November 2019) E/C.12/ECU/CO/4, paras. 5, 6 (b) and 46.

32 CESCR, 'Concluding Observations on the second periodic report of Israel' (26 June 2003) E/C.12/1/Add.9o, para. 31; 'Concluding Observations on the initial report of Mali' (6 November 2018) E/C.12/MLI/Co/1, paras. 4-5 (a), 45 and 46 (a). CESCR, Marcia Cecilia Trujillo Calero v. Ecuador (14 November 2018) E/C.12/63/D/10/2015, para. 14.3.

34 Toebes et al. (n 26).

35 See General Comment No. 3 (n 27); CEscr, 'An Evaluation Of The Obligation To Take Steps To The 'Maximum Available Resources' Under An Optional Protocol to the Covenant. Statement' (10 May 2007) E/C.12/2007/1, para. 10 (b); and Toebes et al. (n 26). 


\section{Relevance of the Right to Health during the covid-19 Pandemic}

This Section discusses the relevance of the right to health during the CoviD-19 pandemic and the added value of its realisation for the purposes of an effective pandemic response. It evaluates UNM B's views that shed light on the import of essential components of the normative content of the right to health in the context of the pandemic coupled with an overview of relevant trends in State practice. Said trends cover the period March 2O2O-May 2021. The UNMB this Section considers are the CESCR, the CEDAW, the CRPD, the Committee on the Elimination of Racial Discrimination (CERD), the Committee on the Rights of the Child (CRC), the Committee on Migrant Workers (CMW), the UN Special Procedures (UNSPs), the Special Rapporteur on the human rights of migrants (SRM), and the Special Rapporteur on the right to health (SRRTH).

This Section examines constituent components of the contour of the right to health that feature in the conceptual framework the CESCR developed in its highly authoritative General Comment No. 14 and reproposes in its December 2020 Vaccines Statement. Based on the Committee's framework this Section first analyses entitlements implied in the right to health. Subsequently, this Section focuses on the essential elements of the right to health the Committee has illuminated in order to define more clearly the scope of relevant State obligations: availability, accessibility, acceptability, and quality. ${ }^{36}$ The CESCR has construed the notion of accessibility as implying non-discriminatory, physical and economic access to health care as well as access to information on health issues. ${ }^{37}$ For the purposes of this Section, however, only the import of accessibility meant as non-discriminatory access to health care will be explored.

The import of the above constituent elements of the right to health in the context of the COVID-19 pandemic is elucidated through reliance on the CESCR' S Vaccines Statements of December 2020 and April 2021; the CESCR' S April 2020 Statement on COVID-19 and ESCR; the UN SPs' 2020 Statements on COVID-19 and on universal access to COVID-19 vaccines; the CMW and the SRM's Guidance Notes on the COVID-19 pandemic and the human rights of migrants and on equitable access to CoviD-19 vaccines for migrants; the SRRTH's July 2020 report to the UN General Assembly; CEDAW's Guidance Note on COVID-19 and the UN Women Convention; the CRPD' Statement on

36 General Comment No. 14 (n 12) Part I; CESCR, 'Statement on universal and equitable access to vaccines for the coronavirus disease (COVID-19)' (15 December 2020) E/C.12/2020/2, paras. 2 and 4 . 
COVID-19 and persons with disabilities; the CERD' Statement on the COVID19 pandemic and State obligations under the ICERD; and the CRC's COVID-19 Statement.

\subsection{The Rights to Access COVID-19 Vaccines and Treatment}

The UNMB have construed the right to health as encompassing the rights to access COVID-19 treatment and vaccines. Accordingly, the UNSPs have interpreted the right to health as implying a right to COVID-19 life-saving interventions. ${ }^{38}$ In its December 2020 Vaccines Statement the CESCR has maintained that the right to access a safe and effective coviD-19 vaccine is part of the contour of the right to health in so far as the right to health includes 'access to immunization programs against the major infectious diseases.' ${ }^{39}$ The CMW and the SRM's interpretation of the right to health in the context of the Covid-19 pandemic bears out that the right to health implies the right to access COVID-19 vaccination. ${ }^{40}$

In the December 2020 Vaccines Statement the CESCR indirectly posits that the right to health also incorporates the right to access CoviD-19 treatment. The Committee acknowledges in paragraph 12 that the main points made vis-à-vis access to COVID-19 vaccines throughout the statement 'are relevant, mutatis mutandis, to the obligations of States to also ensure universal and equitable access to treatment for COVID-19. Hence, applying the interpretative approach the Committee uses to extrapolate the right to access a safe and effective covid-19 vaccine, it can be argued that the right to health incorporates the right to access COVID-19 treatment because the right to health implies the right to access health facilities, goods and services. ${ }^{41}$ In its April 2020 Statement on COVID-19 and ESCR the Committee explains that COVID-19 treatment encompasses COVID-19 equipment, testing and health care services. ${ }^{42}$ The other UNM B complement the Committee's view by suggesting that said treatment also includes: early detection, personal protective equipment for health-care workers and other front-line staff, diagnostic tests, ventilators, and oxygen ${ }^{43}$

38 онснR, 'No exceptions with COVID-19: "Everyone has the right to life-saving interventions" - UN experts say' (2020).

39 CESCR, 2020 Vaccines Statement (n 36$)$ para. 2.

40 OHCHR, 'Joint Guidance Note on Equitable Access to COVID-19 Vaccines for all Migrants', $2<$ https://www.ohchr.org/Documents/Issues/Migration/JointGuidanceNoteCOVID-19 -Vaccines-for-Migrants.pdf $>$.

41 See General Comment No. 14 (n 12$)$ paras. 9 and 17.

42 CESCR, 'Statement on the coronavirus disease (COVID-19) pandemic and economic, social and cultural rights', (17 April 202O) E/C.12/2O2O/1, para. 9 .

43 OHCHR, 'No exceptions with COVID-19' (n 38); CEDAW 'Guidance Note on CEDAW and COVID-19' (2020), para. 1; UNGA, 'Final report of the Special Rapporteur on the right of 
The UNMB's interpretation of the right to health as implying the rights to access COVID-19 vaccines and treatment is especially relevant during the COVID-19 pandemic since it triggers individuals and communities' participation in pandemic responses and government accountability. Said interpretation points out that individuals and communities are rights holders and that they can invoke the rights to access CoviD-19 vaccines and treatment to pressure governments to devise pandemic responses that guarantee equal and effective access to COVID-19 treatments. ${ }^{44}$ Individual and groups can also rely on the interpretation at hand in domestic legal proceedings to buttress their claims that government authorities have violated relevant domestic legislation on access to COVID-19 treatment and vaccines. ${ }^{45}$

The члмв have emphasised that the realisation of the rights to access COVID-19 vaccines and treatment hinges upon the operationalisation of the above essential elements inherent in the right to health: availability, accessibility, acceptability, and quality. ${ }^{46}$ The next Sub-sections explore what these elements entail during the CoviD-19 pandemic.

\subsection{Availability of covID-19 Treatment}

Based on General Comment No. 14 availability requires that health facilities, goods and services are available in a sufficient quantity within the territory of a State party to the ICESCR. ${ }^{47}$ In its December 2020 Vaccines Statement the CESCR clarifies that in the context of the COVID-19 pandemic the availability requirement further necessitates that States ensure that sufficient quantities of

everyone to the enjoyment of the highest attainable standard of physical and mental health, Dainius Pūras', (July 2020) A/75/163, para. 54; CERD, 'Statement on the Coronavirus (COvID-19) Pandemic and its Implications under the International Convention on the Elimination of All Forms of Racial Discrimination', in онCHR, Compilation of Statements by Human Rights Treaty Bodies in the Context of CoviD-19 (September 2020), 49, para. 4 (a); CMW and SRM, 'Joint Guidance Note on the Impacts of the covid-19 Pandemic on the Human Rights of Migrants' (26 May 2020), 2.

44 On community participation in pandemic responses see also: Cicely Marston et al., 'Community participation is crucial in a pandemic' (2020) 395 Lancet, 1676-1678; and Patrick Eba, 'Ebola and human rights in west Africa' (2014) 384 Lancet, 2091-2093.

45 See generally: онснR, 'Human Rights in the Administration of Justice: A Manual on Human Rights for Judges, Prosecutors and Lawyers' (2003) 20-24 <https://www.ohchr .org/Documents/Publications/training9Titleen.pdf>.

46 CESCR, 2O2O Vaccines Statement (n 36) para. 4; онСнR, 'No exceptions with Covid-19' (n 38); онснR, 'Joint Guidance Note on Equitable Access to Covid-19 Vaccines for all Migrants, (n 40).

General Comment No. 14 (n 12) para. 12 (a). 
COVID-19 vaccines and, by extension, treatment are produced and made available within their jurisdictions. ${ }^{48}$

The Committee does not offer guidance on how States should operationalise the availability requirement. In its April 2020 Statement it limits itself to indicate that COVID-19 treatment encompasses COVID-19 equipment, testing and health care services. ${ }^{49}$ Nevertheless, it is submitted that State parties to the ICESCR should implement the obligation to make COVID-19 treatment available within their territory as a matter of priority since said obligation is the pre-condition for giving effect to the maximum priority obligation to ensure universal and equal access to COVID-19 treatment which, as shown in Sub-section 3.3, arises from the accessibility requirement. Also, States should use all the resources they have at their disposal to make COVID-19 treatment available including, based on Article 2 (1) of the ICESCR, those obtainable through international assistance and cooperation. ${ }^{50}$

Besides not elaborating on the implementation of the availability requirement at the national level, the Committee omits a teleological explanation of why availability of COVID-19 treatment cannot be overlooked when responding to the CoviD-19 pandemic. While one may argue that said explanation is implied in the Committee' Statements, it would have been desirable that the Committee emphasized more forcefully that availability of CoviD-19 treatment is essential to containing the health risks posed by the novel coronavirus infection; adequately treating those affected by it; reducing its staggering death toll; and eventually putting an end to it. By doing so the Committee would have illuminated the relevance of the availability requirement during the pandemic more convincingly and compellingly and put more pressure on States to operationalise it.

The SRRTH, on the other hand, has dwelled on the centrality of availability of COVID-19 treatment for the purpose of tackling the COVID-19 pandemic in his July 2020 report to the UN General Assembly. After suggesting that availability of covid-19-related health coverage is an integral aspect of the realisation of the right to health during the pandemic, ${ }^{51}$ the expert powerfully maintained

48 CESCR, 2O20 Vaccines Statement (n 36) paras. 4 and 12; and CESCR, 'Statement on universal and affordable vaccination against coronavirus disease (CoviD-19), international cooperation and intellectual property' (23 April 2021) E/C.12/2021/1, para. 1. CESCR, April 2020 Statement (n 42).

50 General Comment No. 14 (n 12) para. 38; and онснR, 'Statement by UN Human Rights Experts Universal access to vaccines is essential for prevention and containment of COVID-19 around the world' (2O2O). 
that stopping the spread of the novel coronavirus 'cannot be achieved without well-resourced [...] health systems.' ${ }^{52}$

The CEDAW has analysed availability of COVID-19 treatment through a gender lens thereby adding an important perspective to the CESCR' Statements and the Rapporteurs' views. CEDAW has deemed availability of COVID-19 treatment critical to addressing women's increased risk of contracting coviD19 arising from their role as care givers and their high representation in the health workforce. ${ }^{53}$

The implementation of the availability requirement has been challenging during the COVID-19 pandemic. As lamented by the SRRTH, and confirmed by scholars, many States have experienced 'shortages in essential medical care, including diagnostic tests, ventilators, and oxygen, and in personal protective equipment for health-care workers'. ${ }^{44}$ The management of the pandemic between March and November 2020 in Italy further illustrates obstacles to the operationalisation of the availability requirement.

Italy's response to the COVID-19 pandemic in March 2020 was highly inadequate due to lack of preparedness and availability of Covid-19 treatment. ${ }^{55}$ As a result, the Italian health system was under enormous pressure with hospitals suffering from lack of personnel, ventilators, hospital beds, ICU beds, and protective equipment and testing for health care workers. ${ }^{56}$ The government, however, reacted fairly quickly to grapple with the unavailability of COVID-19 treatment. As Sanfelici noted, starting in March 2020 '[n] ew hospitals were built and many [were] converted into coviD-19 hospitals'.57 In early April, the number of ICU beds almost doubled while beds in departments for infection and respiratory diseases quadrupled. ${ }^{58}$ Availability of ventilators

\footnotetext{
$52 \quad$ Ibid.

53 CEDAW, 'Guidance Note' (n 43) para. 1.

54 Final report of the SRRTH, (n 43) para. 54. See also: Sharifah Sekalala et al., 'Health and human rights are inextricably linked in the CoviD-19 response' (2O20) 5/9 BJM, 4.

55 Maria Sanfelici, 'The Italian Response to the CoviD-19 Crisis: Lessons Learned and Future Direction in Social Development' (2020) 2/2 The International Journal of Community and Social Development, 191-210, <https://journals.sagepub.com/doi/full/ 10.1177/2516602620936037>; Angela Giuffrida, 'Italy 'misled wHO on pandemic readiness' weeks before COvID outbreak' The Guardian (22 February 2021) <https://www.the guardian.com/world/2O21/feb/22/italy-misled-who-on-pandemic-readiness-weeks -before-covid-outbreak>.

56 Sanfelici ( $\mathrm{n}_{55}$ ).

57 Ibid.

58 Invitalia, 'Arcuri: con gli Incentivi \#curaitalia Approvati 30 Progetti per 13,6 Milioni di Investimenti' (4 April 2020) <https://www.invitalia.it/chi-siamo/area-media/notizie-e -comunicati-stampa/conferenza-stampa-commissario-straordinario-4-aprile>.
} 
increased up to $31 \%,{ }^{59}$ and $€_{13}, 6$ million were invested in the production of new personal protective equipment. ${ }^{60}$ Also, the Ministry of Health announced the recruitment of 'community' nurses and social workers to provide integrated health services on the territory. ${ }^{61}$ Competent authorities coupled the increase of the availability of CoviD-19 treatment with the implementation of containment measures, which included, inter alia, lockdowns and social distancing. ${ }^{62}$ Through this two-pronged approach Italian authorities turned around an initially flawed pandemic response, ${ }^{63}$ and contained the first wave of the CoviD-19 pandemic with the result that at end of July 2020 Italy's hospitals were 'basically empty of Covid-19 patients' ${ }^{64}$ Unfortunately, in Fall 2020 Italy was battling a second and more powerful wave of the novel coronavirus infection. ${ }^{65}$ Experts ascribed this regression to relaxation of the above containment measures and expressed concern about Italy's ability to respond to the new phase of the pandemic owing to delays in the provision of additional ICU beds and ventilators; shortage of anaesthetists; and delays in testing. ${ }^{66}$

The SRRTH'S assessment of State practice and the Italy case show that a right to health-based approach has the added value of ensuring that States never overlook availability of CoviD-19 treatment or implement it inconsistently when managing the CoviD-19 pandemic. This is so because the right to health obligates States to ground pandemic strategies in the availability requirement and to prioritise its operationalisation. ${ }^{67}$ States are expected to plan, assemble and organise throughout the pandemic the human, financial and material resources that will be necessary to respond to it. Countries thus

$59 \quad$ Ibid.

6o Ibid.

61 Sanfelici (n 55). On how Italy increased availability of covid-19 treatment see also: Benedetta Armocida et al., 'The Italian health system and the coviD-19 challenge' (2020) 5 The Lancet, 253 <https://www.thelancet.com/action/showPdf?pii=S2468-2667 $\% 2820 \% 2930074-8>$.

62 Chiara Berardi et al., 'The COVID-19 Pandemic in Italy: Policy and Technology Impact on Health and Non-Health Outcomes' (2020) 9/4 Health Policy Technology, 454-487 $<$ https://www.ncbi.nlm.nih.gov/pmc/articles/PMC7467905/>.

63 Ibid; and Jason Horowitz, 'How Italy Turned Around its Coronavirus Calamity', The New York Times (31 July 2020).

64 Horowitz (n 63).

65 Marta Paterlini, 'Covid:19: Italy has wasted the sacrifices of the first wave, say experts' (2020) $371 \mathrm{BMJ}, 2$.

66 Ibid., $1-2$.

67 онснк, 'COVID-19 Measures Must be Grounded First and Foremost on the Right to Health' (2020); Sharifah Sekalala (n 54) 1; Sharifah Sekalala et al., 'An Intersectional human rights approach to prioritizing access to CoviD-19 vaccines' (2O21) 6/2 BMJ, 4; Gostin (n 11) 624 . 
will be well equipped to promptly tackle the challenges the pandemic poses and able to sustain provision of health care for its entire duration, including when there may be a recrudescence of infections following a period of successful mitigation.

\subsection{Accessibility of covID-19 Treatment}

For the CESCR accessibility means first and foremost access to the health care system for all, especially for those most vulnerable or marginalised, without discrimination on any of the internationally prohibited grounds. ${ }^{68}$ As further elucidated in the December 2020 Vaccines Statement, in the context of the COVID-19 pandemic the accessibility requirement entails access on an equal footing to COVID-19 vaccines and, by extension, treatment for all, including disadvantaged groups. ${ }^{69}$

State parties to the ICESCR must take all necessary measures, within the maximum of their available resources, to guarantee universal and nondiscriminatory access to COVID-19 treatment. ${ }^{70}$ States should give high precedence to the implementation of this obligation because it emanates from the core obligations to: a) ensure equal access to health facilities, goods and services for all, especially for those who are marginalised, and b) provide essential medicines. ${ }^{71}$

The CESCR is convinced that, in order to pave the way for equal access to COVID-19 treatment, State parties to the ICESCR will have to remove any discrimination based on the internationally prohibited grounds and any other relevant status. ${ }^{72}$ Consequently, States should bar not only blatant denial of CoviD-19 treatment to individuals who have characteristics corresponding to the prohibited discrimination grounds. States should also address the insidious de facto discrimination in access to COVID-19 treatment by 'paying sufficient attention to groups of individuals which suffer historical or persistent prejudice. ${ }^{73}$

68 General Comment No. 14 (n 12) para. 12 (b) (i).

69 CESCR, 2020 Vaccines Statement $\left(\mathrm{n}_{3} 6\right)$ paras. 4 and 12.

$70 \quad$ Ibid., paras. 3 and 12.

71 General Comment No. 14 (n 12) para. 43 (a) and (d); and CESCR, April 2020 Statement (n. 42) para. 12 stating that the core obligations flowing from the ICESCR rights should be prioritised.

72 CESCR, 2O2O Vaccines Statement (n 36) paras. 4. and 12.

73 CESCR, 'General Comment No. 20. Non-discrimination in economic, social and cultural rights (art. 2, para. 2, of the International Covenant on Economic, Social and Cultural Rights)' (2 July 2009) E/C.12/GC/2O, para. 8 (b). 
The SRRTH has understood non-discriminatory access to COVID-19 treatment in terms of universal health coverage. ${ }^{74} \mathrm{He}$ has pointed out that this fundamental element of the right to health is essential to putting an end to the pandemic and developing and enhancing 'social justice and social cohesion.' ${ }^{75}$ He has underscored however that universal access to Covid-19 treatment has been difficult to achieve even in countries where health facilities were available since 'there has been discrimination in the selection of individuals who could get tested and treated, with groups in marginalized situations missing out as care was rationed, including Roma, people of African descent and older persons. ${ }^{76}$

Discrimination in access to COVID-19 treatment suffered by marginalised groups has also prompted the SRRTH to send communications to certain UN member States. These communications allow the conclusion that the accessibility requirement further entails that provision of COVID-19 treatment to marginalised groups must be tailored to their unique health needs and that such needs must be addressed by national pandemic plans. Thus, in May 2020 the Rapporteur wrote to Romania where there had been CoviD-19 outbreaks in various residential homes and the older persons living there were afforded substandard CoviD-19 treatment on site while the homes' staff was treated at nearby hospitals. ${ }^{77}$ The Rapporteur stressed that Article 12 of the ICESCR obligates States to adopt an integrated approach when providing health care to older persons, implicitly suggesting that the older persons sheltered in the residential homes at stake should receive, given their predicament, preventive, curative and rehabilitative COVID-19 treatment. ${ }^{78}$ Romania was asked to provide information on the steps undertaken to safeguard older persons' right to health and to clarify what happened in the residential homes in question. ${ }^{79} \mathrm{In}$ June 2020 the Rapporteur wrote to Russia ${ }^{80}$ to request information on measures taken to ensure that persons with disabilities had access to health care on an equal basis in the context of the COVID-19 pandemic, and on whether

\footnotetext{
$74 \quad$ Final report of the SRRTH (n 43) para. 51.

75 Ibid., and paras. 51 and 54 .

76 Ibid., para. 55 .

77 SRRTh, Communication sent to Romania on 19 May 2020, UA ROU 1/2020, $2-3<\mathrm{https} / / /$ spcommreports.ohchr.org/TMResultsBase/DownLoadPublicCommunicationFile ?gId $=25271>$.

78 Ibid., 3 and 5 .

79 Ibid., 6.

8 O SRRTH, Communication sent to Russia on 10 June 2020 , AL RUS $3 / 2020,<\mathrm{https} / / /$ spcomm reports.ohchr.org/TMResultsBase/DownLoadPublicCommunicationFile?gId=25334>.
} 
the national pandemic plan dealt with the specific situation of "all" these persons. ${ }^{81}$

The CRPD has been specifically concerned with the de-prioritisation of persons with disabilities in accessing CoviD-19 treatment. ${ }^{82}$ It has stressed that State parties to the UNCRPD should provide persons with disabilities with access to life-saving services with the same range, quality and standard of health care as provided to other persons. ${ }^{83}$ The CRPD has also encouraged States to consider the health needs of persons with disabilities experiencing intersectional discrimination 'with a particular focus on gender and age, and the situation of persons with disabilities facing deprivation and hardship. ${ }^{84}$

Similarly, the CMW and the SRM have urged States to facilitate nondiscriminatory access to COVID-19 treatment for migrant workers through the development of pandemic plans that take into account these persons' gender and age. ${ }^{85}$ Additionally, the Committee and the Rapporteur have called on States to adopt measures for the prevention of the spread of CoviD-19 in shelters and structures for the reception of migrants and to provide these persons with access to COVID-19 treatment based on the principle of 'equivalence of care. ${ }^{86}$ Moreover, the Committee and the Rapporteur have remined States of the situation of migrants living in densely concentrated areas since said persons are especially exposed to COVID-19 and should have equal access to COVID-19 treatment irrespective of their migration status. ${ }^{87}$

The CERD has also addressed migrants' access to COVID-19 treatment. In its 2020 COVID-19 Statement the Committee noted with concern that migrants as well as the Roma, Indigenous Peoples, people of African descent, asylum seekers, refugees and other groups who face discrimination based on descent were being disproportionately affected by the pandemic, including in the exercise of their right to health. ${ }^{88}$ As a result, the Committee urged State parties to honour their obligations under the ICERD so as to ensure that the above groups access

\footnotetext{
81 Ibid., 3 .

82 Audry Lebrasseur et al., 'Impact of covid-19 on people with physical disabilities: A rapid review' (2020) 1/1 Disability and Health Journal, 101014.

83 OHCHR, 'Joint Statement: Persons with Disabilities and Covid-19 by the Chair of the United Nations Committee on the Rights of Persons with Disabilities, on behalf of the Committee on the Rights of Persons with Disabilities and the Special Envoy of the United Nations Secretary-General on Disability and Accessibility' (2020) para. 7 .

84 Ibid.

85 CMW and SRM, 'Join Guidance note on the Impacts of the COVID-19 Pandemic' (n 43) para. 2.

86 Ibid., paras. 8 and 11.

87 Ibid., para. 10.

88 CERD' Statement on the Covid-19 Pandemic (n 43 ) 47 and 49, para. 4 (a).
} 
COVID-19 testing, medicines and medical procedures on a non-discriminatory basis. ${ }^{89}$

The CEDAw, on the other hand, has dwelled on access to CoviD-19 treatment by women in general and those disadvantaged as a result of intersectional discrimination. In its view, State parties to the UNCEDAW must tackle women's exposure to COVID-19 by ensuring that they access treatment of COVID-19. ${ }^{90}$ At the same time States must adopt 'targeted measures' 91 for older women and indigenous women. Older women should be able to access CoviD-19 treatment through medical home visits and safe transport to health care facilities. Indigenous women should access 'culturally acceptable healthcare, aiming at an integrated approach between modern medicine and indigenous traditional medicine, including access to [...] CoviD-19 [treatment]. ${ }^{92}$

Finally, the CRC has encouraged State parties to the UNCRC not to deny children access to COVID-19 treatment and not to discriminate against specific groups of children when managing the pandemic, ${ }^{93}$ including, consequently, when responding to the public health challenges it poses. These children are children with disabilities; children living in poverty; those in street situations; asylum seeker children; migrant children; refugee and internally displaced children; minority and indigenous children; children with underlying health conditions; children deprived of their liberty; and children living in institutions. ${ }^{94}$

The UNMB's views reveal another important added value of the implementation of the right to health during the COVID-19 pandemic. By requiring that States do not leave anybody behind when facilitating access to COVID-19 treatment, especially marginalised groups, the right to health contributes to shape inclusive, fair and successful pandemic responses. The notion of accessibility of COVID-19 treatment revolves around the predicaments of marginalised groups who face barriers when accessing COVID-19 treatment owing to different and intersecting forms of discrimination. States are required to be mindful of these groups' health needs and incorporate targeted measures aimed at making COVID-19 treatment accessible for them into pandemic responses. Specifically, governments must tailor these measures to the various health needs of the

\footnotetext{
$89 \quad$ Ibid., 49, para. 4 (a).

$90 \quad$ CEDAW, 'Guidance Note' (n 43) para. 1.

91 Ibid., para. 7 .

92 Ibid.

93 CRC, 'The Committee on the Rights of the Child warns of the grave physical, emotional and psychological effect of the CoviD-19 pandemic on children and calls on States to protect the rights of children' (8 April 2020) paras. 5 and 7. 
groups at hand; implement these measures as a matter of priority; and, as the CEDAW, the CERD and the CRPD further suggest, with the direct input of the above groups or representative organizations, ${ }^{95}$ thereby maximising the effectiveness of pandemic responses.

The notion of accessibility also applies to COVID-19 vaccines and, as shown below, further leads to pandemic responses that are fair by requiring that disadvantaged groups most at risk of CoviD-19 and people living in developing countries access vaccines on an equal footing.

\subsubsection{Access to COVID-19 Vaccines at the National Level}

The CESCR and the UNSPS have been particularly concerned with the accessibility of COVID-19 vaccines at the national level.

As mentioned in the previous Sub-section, in its December 2020 Vaccines Statement the CESCR has made clear that the accessibility requirement necessitates ensuring non-discriminatory access to COVID-19 vaccines. ${ }^{96}$ The Committee has further maintained that State parties to the ICESCR must perform this obligation using the maximum of their available resources. ${ }^{97}$ The Committee has extrapolated said obligation from the obligation to provide immunization programs against major infectious diseases and the obligation to prevent and control epidemics previously developed in paragraph 44 of General Comment No. $14 .{ }^{98}$ Given that these two obligations are as fundamental as the core obligations, ${ }^{99}$ the Committee expects States 'to give maximum priority to the provision of vaccines for COVID-19 to all persons'.100

While the Committee does not expressly say so, compliance with this obligation to facilitate non-discriminatory access to COVID-19 vaccines presupposes that States make available and administer sufficient quantities of the vaccines. ${ }^{101}$ Sates have resorted to different options to make CoviD-19 vaccines available. Some States have funded research institutes or pharmaceutical companies that have produced vaccines those States have subsequently distributed and administered. ${ }^{102}$ Other States have purchased the vaccines from

95 CEDAW, 'Guidance Note' (n 43) para. 4; CERD, 'Concluding Observations on the combined twentieth to twenty-second periodic reports of Belgium' (21 May 2021) CERD/C/BEL/ CO/2O-22, para. 23 (f); ОHCHR, 'Joint Statement on persons with disabilities' (n. 83).

96 CESCR, 2020 Vaccines Statement (n 36$)$ para. 4.

97 Ibid., para. 3.

98 Ibid.

$99 \quad$ Ibid.

100 Ibid.

101 Ibid., para. 4.

102 Chris Baraniuk, 'COVID-19: What do we know about Sputnik V and other Russian vaccines?' (2021) 372/743 BMJ, 1-2; 'Sinopharm: Chinese Covid vaccine gets WHO emergency approval' (7 May 2021) <https://www.bbc.com/news/world-asia-china-56967973>. 
pharmaceutical companies such as Pfizer, Moderna, Johnson and Johnson, and Astra Zeneca and administered them thereafter. ${ }^{103}$

The CESCR has acknowledged that initially it will be impossible to guarantee that everyone has timely access to CoviD-19 vaccines, due to complex administrative and health procedures inherent in their mass production and distribution. ${ }^{104}$ Based on the fundamental prohibition of discrimination, medical needs and public health grounds, the Committee takes the view that the following groups could be vaccinated first: a) health staff and care workers; b) persons whose health condition may seriously deteriorate if infected by COVID-19 because of age, or pre-existing conditions; or c) populations most exposed to COVID-19 because of lack of access to the social determinants of health such as marginalised migrants; refugees and asylum seekers; persons living in informal settlements or dense housing; prisoners; the poor; displaced persons; and Indigenous Peoples. ${ }^{105}$ Reading the CESCR's view together with the CMW and the SRM 's Note on access to COVID-19 vaccines for migrants, it is safe to add that the above marginalised migrants include 'migrants in irregular situations, low-income migrants, migrants living in camps or unsafe conditions, in immigration detention, [and] migrants in transit'.106

The UNSPs take a similar approach to that of the CESCR when in their vaccines Statement affirm that it is imperative that people in vulnerable situations, who are most at risk of CoviD-19 owing to lack of access to health care, should be vaccinated first. The SPs provide a long list of these people which include, in addition to the groups the CESCR has indicated, marginalised and impoverished LGBT persons, older persons, people who use drugs, minority communities, women and persons with disabilities. ${ }^{107}$

The CESCR also identifies procedural criteria that should inform decisions prioritising certain groups of persons when administering vaccines. Said decisions will have to be grounded in the general prohibition of

103 'Canada orders 20 million more doses of Pfizer/BioNTech COVID-19 vaccine: PM', Reuters (12 January 2021) <https://www.reuters.com/article/us-health-coronavirus -canada-pfizer/canada-orders-2o-million-more-doses-of-pfizer-biontech-covid -19-vaccine-pm-idUSKBN29H2AT>; Michel Rose and Philip Blenkinsop, 'Astra Zeneca COVID-19 Vaccine to be shared across Europe, says France', Reuters (15June 2020) <https:// www.reuters.com/article/us-health-coronavirus-vaccines-france/astrazeneca-covid-19 -vaccine-to-be-shared-across-europe-says-france-idUSKBN23 $\mathrm{M}_{5} \mathrm{~T}>$.

104 CESCR, 2020 Vaccines Statement (n 36 ) para. 5.

105 Ibid.

106 OHCRH , 'Joint Guidance Note on Equitable Access to COVID-19 Vaccines for all Migrants' (n 40) 1.

107 OHCRH, 'Statement by UN Human Rights Experts' (n 5o). 
discrimination, medical needs and public health; taken following adequate public consultation and be subject, 'in the event of dispute, to judicial review to avoid discrimination.. ${ }^{108}$ Arguably, the Committee should have reflected more on the nature of 'adequate public consultation' and made plain that for this consultation to be meaningfully participatory it should involve the disadvantaged groups mentioned above and civil society organizations.

The accessibility requirement as interpreted by the CESCR and the SPS in relation to COVID-19 vaccines reinforces the fairness and inclusiveness of pandemic responses by requiring that States put in place vaccination programs that are based not only on epidemiological grounds but also on social justice. States are expected to give precedence in their vaccination efforts to persons most at risk of COVID-19 owing to their occupation, health status and age, as well as to those most exposed to CoviD-19 because they do not have access to health care and social determinants of health on an equal footing. 109

State practice highlights a trend that partly reflects the CESCR'S approach. States have phased vaccinations by inoculating first health care and front-line workers; persons with pre-existing medical conditions; and those aged 60 and over. Subsequently, vaccinations have been administered to the entire adult population. ${ }^{110}$ Regrettably, there appears to be lack of attention to marginalised groups. As reported, as of Spring 2021 in many countries Indigenous populations, racial minorities and the working poor were disproportionately affected by COVID-19; in southeast Asia migrant workers were not prioritised for vaccinations despite being at high risk for COvID-19 due to their poor living conditions; displaced persons were marginally included in CoviD-19 vaccine efforts; and the Rohingya refugees from Myanmar were deliberately excluded. ${ }^{111}$

\subsubsection{Global Access to COVID-19 Vaccines}

Ensuring access to COVID-19 vaccines has been fraught with difficulties not only at the national level. In Fall 2020 rich countries signed agreements with pharmaceutical companies to obtain preferential access to COVID-19 vaccines

108 CESCR, 2020 Vaccines Statement (n 36$)$ para. 5 .

109 See also: Sharifah Sekalala (n 67) 4-6.

110 Ibid., 3; Leng Shumei, 'Beijing has vaccinated some people aged 6o and above, will inoculate teenagers based on clinical trials: Beijing CDC', Global Times (1 March 2021); CERN, 'Covid-19 vaccination for residents in France (2021) <https://chis.cern/covid -19-vaccination-residents-france>; Gareth Iacobucci, 'COVID-19: NHS will prioritise four most at risk groups for second doses, says Steven' (2O21) 372/252 BMJ.

111 The International AIDS Society - Lancet Commission on Health and Human Rights, 'Human rights and fair access to vaccines' (2021) 397 The Lancet <https://www.thelancet .com/journals/lancet/article/PIISo140-6736(21)oo7o8-X/fulltext>. 
to the detriment of developing countries. ${ }^{112}$ By the end of May 2021 not enough vaccines had been produced and those already produced or ordered had been administered in high-income countries. ${ }^{113}$ At the time of writing half of Americans and more than a quarter of Europeans had received at least one dose of COVID-19 vaccines while only $14 \%$ of people in South America, $4.8 \%$ in Asia and $1.2 \%$ in Africa had been vaccinated. ${ }^{114}$

In its 2020 and 2021 Vaccines Statements the CESCR has made unmistakably clear that if State parties to the ICESCR do not duly foster implementation of the right to access a CoviD-19 vaccine worldwide more people will die, the effectiveness of the vaccines will be undermined by the emergence of more contagious and fatal variants of the novel coronavirus, and the vaccines will not deliver their 'full potential to control the pandemic'.115 The Committee has reminded States that the obligation to take all the necessary measures, as a matter of priority and to the maximum of their available resources, to guarantee non-discriminatory access to COVID-19 vaccines has an international dimension since 'many States worldwide do not produce vaccines themselves'. ${ }^{16}$ This means giving effect to the obligation of international assistance and cooperation set out in Article 2 (1) of the ICESCR, which in relation to the right to access COVID-19 vaccines requires State parties to develop strategies and mechanisms to ensure sufficient production and equitable distribution of COVID-19 vaccines 'whenever needed'.117 Similarly, the SPs have urged States to devise a pandemic response predicated on 'the bedrock human-rights based principles of international solidarity, cooperation and assistance' 118

Both the Committee and the sps have recommended various measures that States, especially the most developed ones, should take to rectify the lack of

112 CESCR, 2021 Vaccines Statement (n 48) para. 4; OHCHR, 'Statement by UN Human Rights Experts' (n 5o).

113 CESCR, 2021 Vaccines Statement (n 48) para. 1; Tim Fish Hodgson, 'Human Rights and Universal Access to Covid-19 Vaccines: Does the Human Rights Council Resolution Go far enough?' (2021) Opinio Juris <http://opiniojuris.org/2021/o3/23/human-rights-and -universal-access-to-covid-19-vaccines-does-the-human-rights-council-resolution-go-far -enough/>.

114 'The pandemic fire is still raging. Rich-country leaders must respond', Washington Post Editorial (1 June 2021).

115 CESCR, 2021 Vaccines Statement (n 48) para. 1; CESCR, 2020 Vaccines Statement (n 36) para. 10.

116 CESCR, 2021 Vaccine Statement (n 48) para. 3. For further analysis on the scope of the obligation of international assistance and cooperation in the context of the pandemic see: Oona A. Hathaway (n 8); and Sharifah Sekalala (n 54) 4-5.

117 CESCR, 2020 Vaccines Statement (n 36$)$ para. 9.

118 OHCHR, 'Statement by UN Human Rights Experts' (n 5 o). 
access to and, by extension, the lack of availability of covid-19 vaccines worldwide. These States have been exhorted to: a) join the wHO-supported covax Global Vaccines Facility for equitable access to vaccines; b) share medical technologies, including vaccines, intellectual property data, and know-how on vaccines with developing countries; and c) use all the flexibilities of the TRIPS Agreement, especially compulsory licenses, to increase availability and access to safe vaccines in developing countries. ${ }^{119}$ The CESCR and the SPs have also suggested to place a temporary waiver on some of the provisions of the TRIPS Agreement for CoviD-19 vaccines 'at least until global herd immunity for COVID-19 is achieved and the pandemic is considered to be under control.: ${ }^{120}$ The Committee deems the waiver an essential strategy for enhancing access to vaccines globally given that implementation of the TRIPS flexibilities is lengthy and complex and may, therefore, limit the ability of countries that can produce vaccines to export them to countries in need. ${ }^{121}$

The CESCR and the SPs have illuminated for States a number of important and straightforward measures instrumental in realising the right to access COVID-19 vaccines without discrimination at the global level. The Committee and the sps further highlight that a right to health-based approach to the pandemic has the advantage of rendering pandemic responses especially fair because it requires that developed States collaborate with developing States to support vaccination schemes in the latter so that no country is left behind in vaccination efforts. By not leaving any nation behind the international community will be able to achieve global herd immunity, contain the CoviD-19 infection more effectively, and eventually put an end it. It is then for States to follow-up on the Committee and Sps' recommendations. On 5 May 2021, the U.S. announced that it would support the waiver on intellectual property rights for the COVID-19 vaccines. ${ }^{122}$ Since the U.S. has signed but not ratified the ICESCR, this move signals compliance with the international customary law obligation requiring signatory States not to engage in conduct that goes against the object and purpose of a treaty. The U.S. announcement does not simply honour the obligation not to defeat the purpose of realising the right to access COVID-19 vaccines globally as required under Article 12 of the Covenant. It may be consequential from the standpoint of vaccine diplomacy since it will put pressure on other developed States opposing the waiver, many of which

119 Ibid., CESCR, 2021 Vaccine Statement (n 48) paras. 6, 9, 10 and 13; оHCHR, 'UN Experts: G7 Governments must ensure vaccines' access in developing countries' (2021).

120 CESCR, 2021 Vaccines Statement (n 48) para. 12; OHCHR, 'COVID-19: UN experts urge WTO cooperation on vaccines to protect public health' (2O21).

121 CESCR, 2021 Vaccine Statement (n 48) paras. 10-11.

122 Statement from Ambassador Katherine Tai on the covid-19 Trips Waiver, 5 May 2021. 
are parties to the ICESCR, to follow suit. Time will tell if the Biden administration' support for the waiver will trigger the consensus or the three-quarter majority necessary for the WTO to apply the waiver, ${ }^{123}$ and State compliance with the ICESCR obligation to engage in international cooperation and assistance to ensure access to COVID-19 vaccines worldwide. As of 28 May 2021, the waiver had ' 62 co-sponsors and [was] supported by more than 100 of the WTO's 164 members.' 124

\subsection{Acceptability and Quality}

The UNM B's Statements do not shed much light on the import of the acceptability and quality requirements in the context of the COVID-19 pandemic. The only exceptions are CEDAW's Guidance Note and the Communication the SRRTH sent to Cambodia in December 2020 involving the publication by the Cambodian Ministry of Health of personal information of patients who had contracted COVID-19.125 The Guidance Note states that during the pandemic Indigenous women and girls should have access to culturally acceptable healthcare, aiming at an integrated approach between modern medicine and indigenous traditional medicine, including access to [...] COVID-19 [treatment].126 The SRRTH's communication allows the inference that a State cannot disclose personal information of Covid-19 patients to identify and provide CoviD-19 treatment to persons who had been exposed to those patients. ${ }^{127}$ The disclosure would breach the principle of patient confidentiality inherent in the acceptability requirement. ${ }^{128}$ Drawing on General Comment No. 14 and views of scholars, it could be further argued that the acceptability requirement also entails that administration of COVID-19 vaccines should respect patient confidentiality, and that CoviD-19 treatments should improve the health status of those concerned and be based on their consent. ${ }^{129}$ The quality requirement would, on the other hand, necessitate that Covid 19 vaccines and treatment are safe, of good quality and, more generally, medically appropriate. ${ }^{130}$

123 John Zarocostas, 'What Next for a covid-19 Intellectual Property Waiver?' (2021) 397 The Lancet, 1871.

124 Ibid.

125 SRRTH, Communication sent to Cambodia on 10 December 2020, AL KHM 10/2020, 1 $<$ https://spcommreports.ohchr.org/TMResultsBase/DownLoadPublicCommunication File?gId $=25768>$.

126 CEDAW, 'Guidance Note' (n 43) para. 7.

127 SRRTh, Communication sent to Cambodia (n 125) 1-2.

128 Ibid., 5; and General Comment No. 14 (n 12) para. 12 (c).

129 Ibid.; Sharifah Sekalala (n 67) 4; Larry Gostin (n 11) 624.

130 Ibid. 


\subsection{Preliminary Conclusions}

The right to health is especially germane to the CoviD-19 pandemic and essential to stopping it. The rights to access COVID-19 treatment and vaccines taken together with the availability, accessibility, acceptability, and quality requirements have important implications for the purposes of an effective management of the pandemic. Their incorporation in pandemic responses has the added value of shaping responses that: a) foster community's participation and government accountability; b) are well equipped to address the formidable public health challenges CoviD-19 poses; c) are inclusive and successful as they prioritise the satisfaction of the health needs of those most at risk of COVID-19, especially marginalised groups, and provide these persons with COVID-19 treatments specifically tailored to their predicaments; d) are fair since they support vaccination programs worldwide; and e) ensure that COVID-19 treatments are culturally acceptable, respectful of medical ethics and medically appropriate.

The covid-19 Pandemic as a Catalyst for Fulfilling the Long-Neglected Right to Health

Thus far this essay has demonstrated the added value of implementing the international right to health during the CoviD-19 pandemic. Yet there is another aspect of the relationship between the right to health and the pandemic that is noteworthy: the fact that the pandemic can function as a catalyst for fulfilling the right to health after years of blatant neglect. ${ }^{131}$ There are various reasons that help explain such neglect. This article focuses on arguments States put forward against the legal nature of ESCR in 1966 during the drafting of the International Covenant on Civil and Political Rights (ICCPR) and the ICESCR. ${ }^{132}$ In a nutshell, it was maintained that ESCR are not true legal rights because they are positive rights the implementation of which always necessitates adoption of certain measures by the State, requires governmental allocation of financial resources and is subject to progressive realisation. ${ }^{133}$

\footnotetext{
131 Philp Alston ( $\mathrm{n}_{1}$ ).

132 Magdalena Sepúlveda, The Nature of Obligations under the International Covenant on Economic, Social and Cultural Rights (Intersentia 2003) 116-136. Other factors that help explain why ESCR were neglected by the International Community are mentioned by Sepulveda at 117. For further analysis see: Riccardo Pisillo Mazzeschi, Responsabilité de l'État pour violation des obligations positives relatives aux droits de l'homme, Recueil des Cours Adi, vol. 333 (2009), 175-506.

133 Magdalena Sepúlveda (n 132) 123, 126-127 and 128.
} 
Civil and political rights, on the other hand, were considered true rights because they are negative, i.e. they obligate the State to refrain from engaging in conduct that would violate them, and hence cost-free and amenable to immediate implementation. ${ }^{134}$ That civil and political rights are amenable to immediate implementation while ESCR are subject to progressive realisation is also reflected in the wording of Article 2 (1) of the ICESCR and Article 2 of the ICCPR. While the former provision requires State parties to the ICESCR to take steps with a view to achieve "progressively" the realisation of Covenant rights, no mention of the notion of progressive realisation is contained in the latter provision with regard to the implementation of civil and political rights.

The above arguments contributed to hamper the fulfillment of the ESCR enshrined in the ICESCR, including the right to health, for more than two decades. At present they are no longer persuasive since there has been an evolution in the perception of ESCR and their implementation. This evolution is evident in: the establishment in 1985 of the CESCR to carry out the monitoring of States' compliance with the ICESCR initially assigned to the ESCOSOC; ${ }^{135}$ the incorporation of ESCR in UN and regional treaties drafted after the ICESCR, many of which also set out civil and political rights; the affirmation in the 1993 Vienna Declaration and Programme of Action that 'all human rights are universal, indivisible and interdependent and interrelated' $; 36$ and the adoption of the 2008 Optional Protocol to the ICESCR, authorizing the CESCR to receive complaints alleging violations of the Covenant rights. ${ }^{137}$ Accordingly, ESCR, including the right to health, are regarded as true legal rights that have the same importance and relevance as civil and political rights. States must thus work towards the realisation of both sets of rights.

Equally important, the practice of human rights monitoring bodies shows that both civil and political rights and ESCR incorporate positive and negative dimensions. Consequently, depending on the dimension that is at stake, civil and political rights may require governmental expenditure and be subject to progressive realisation while ESCR may be amenable to immediate implementation and cost-free. ${ }^{138}$

\footnotetext{
134 Ibid.

135 ECOSOc, Res 1985/17 (28 May 1985).

136 Vienna Declaration and Programme of Action (25 June 1993) para. 5.

137 The text of the Optional Protocol is available at $<$ https://www.ohchr.org/EN/Professional Interest/Pages/OPCESCR.aspx>.

138 See General Comment No. 14 ( $\mathrm{n} 12$ ) para. 34 detailing negative obligations ensuing from the right to health; and Nigel Rodley with Marc Pollard, The treatment of Prisoners under International Law (OUP 2009) 379-425 providing an overview of positive obligations
} 
The pandemic forcefully contributes to the above developments by dramatically and abruptly bringing the right to health to the limelight. As the trends in State practice examined in the previous Section show, the pandemic has laid bare structural problems in the delivery of domestic health care services including lack of COviD-19 treatment, inadequate health infrastructures and discrimination in access to COVID-19 treatments that has compounded marginalisation of certain groups of persons.

Hence, the pandemic becomes a compelling reminder of the importance of the right health and the necessity to operationalise it in line with the interpretations put forward by the UNMB. The pandemic is an invaluable opportunity for States, especially those that are parties to the ICESCR, to refocus and accelerate efforts to implement the right to health and possibly make up for all those years in which this right was overlooked. The most striking evidence that the pandemic is a catalyst for the realisation of the right to health has been the incredibly swift development of COVID-19 vaccines by pharmaceutical companies with, in certain instances, States' financial support. The timely production of the vaccines shows that States can muster efforts and resources to realise the right to health in the most dauting circumstances. As shown in Section 3 , the challenge now is to ensure universal and fair access to the vaccines domestically and globally.

What is more, parties to the ICESCR can, while continuing to meet the short, medium and long-term challenges the pandemic poses, renew efforts to realise the right to health by enhancing the public health sector so that health care can become truly available and universally accessible. State practice seems to go in this direction. At the time of writing South Africa promptly approved a national strategy for infection prevention and control to shield patients and health workers from avoidable infections in health facilities. ${ }^{139}$ The Pakistani government is reinstating immunization and life-saving maternal care to make primary health care more available and accessible to communities. ${ }^{140}$ In France, President Macron promised in March 2020 that 'a massive investment plan [....] will be put in place for [the national] hospital system.. ${ }^{141}$ Italy adopted a Recovery Plan which allocated a significant amount of EU funds for

flowing from the prohibition of torture and ill-treatment as developed by human rights monitoring bodies.

139 WHO, "Responding to COVID-19 and Building Stronger Health Systems for Universal Health Coverage' (2020) <https://www.who.int/news-room/feature-stories/detail/responding-to -covid-19-and-building-stronger-health-systems-for-universal-health-coverage $>$.

140 Ibid.

141 'France's Macron Pledges Massive Investment in Health System after Virus Crisis', Reuters (25 March 2020) <https://www.reuters.com/article/us-health-coronavirus-france-macron/ 
hospitals' renovation, telemedicine, boosting the delivery of health care services regionally and further supporting medical research. ${ }^{142}$

\section{$5 \quad$ Conclusions}

The right to health is inherently relevant to the CoviD-19 pandemic and its implementation during this public health emergency has numerous added values.

First, a right to health-based approach to the pandemic furthers individuals and communities' participation in the development of pandemic responses, and government accountability. The right to health requires that individuals and communities are regarded as rights holders who can use the rights to access COVID-19 treatment and vaccines to pressure governments to devise pandemic responses that guarantee equal and effective access to CoviD-19 treatments. Individuals and groups can also invoke the rights at stake in domestic legal proceedings to buttress their claims that government authorities have violated domestic legislation on access to COVID-19 treatment and vaccines during the pandemic.

Second, the right to health-based approach ensures that States are well equipped to sustain provision of adequate health care throughout the pandemic, including when there may be a recrudescence of infections following periods of successful mitigation, by obligating States to ground their pandemic responses in the requirement to make Covid-19 treatment available and to prioritise its operationalisation.

Third, the right to health helps devise pandemic responses that are fair, inclusive and successful since it encompasses the notion of non-discriminatory access to COVID-19 treatment and vaccines. Accordingly, States are required to be mindful of the predicaments of those most at risk of Covid-19, particularly marginalised groups who do not have access to the health care system owing to various forms of discrimination. States must prioritise these persons when providing COVID-19 treatment and vaccines and ensure that COVID-19

frances-macron-pledges-massive-investment-in-health-system-after-virus-crisis -idUSKBN21 $\mathrm{C}_{3} \mathrm{~F}_{4}>$.

142 Piano Nazionale di Ripresa e Resilienza, 222-233<https://www.governo.it/sites/governo .it/files/PNRR_o.pdf $>$. The plan implements the right to access health care as set out in the European Pillar of Social Rights and can also be considered, in the view of this author, as an indication that Italy is renewing efforts to realise Article 12 of the ICESCR. Furthermore, it has been argued that the pandemic may be the catalyst for realising new rights. See: Neah Jain, 'Pandemics as Rights-Generators', (2020) 114/4 American journal of International Law, 677-686. 
treatments are specifically tailored to their health needs, thereby maximising the effectiveness of pandemic responses. The accessibility requirement is also conducive to equal access to COVID-19 vaccinations worldwide. It necessitates that States fulfil the obligation of international assistance and cooperation by putting in place strategies ensuring that people living in developing countries have access to vaccines on an equal basis with residents of developed countries.

Lastly, the right to health based-approach guarantees that provision of covid-19 treatments is culturally acceptable, safe, effective and based on medical ethics.

Hence, the right to health is an antidote to the COVID-19 pandemic and must be the cornerstone of pandemic responses. ${ }^{143}$ States cannot afford to disregard its implementation if they want to minimise the devastating human and economic costs of the COVID-19 infection. States should, in parentship with individuals, communities and other civil society actors, operationalise the right to health by designing a coordinated and comprehensive pandemic strategy that prioritises the essential elements of this right and gives effect to them simultaneously. ${ }^{144}$

At the same time, the pandemic is functioning as a formidable catalyst for realising the right to health after decades of neglect. As States are increasingly investing in their public health systems to better deal with the CoviD-19 pandemic, States are strengthening these systems by making the health care they deliver more available and accessible, thereby complying with the right to health. These developments are remarkable and hopefully will give 'the impetus for long-term resource mobilization towards the full and equal enjoyment [of the right to health]:.145

143 International Commission of Jurists, 'Living Like People Who Die Slowly: The Need for Right to Health Compliant Covid-19 Responses', (2020).

144 CESCR, April 2020 Statement (n 42), para. 13.

145 Ibid., para. 25 . 